\title{
Investigation and Research on the Current Situation of Football Extracurricular Activities and Soccer Clubs in Independent Colleges in Jiangxi Province
}

\author{
Zhou Rui, Chen Huan, Wu Fan \\ Nanchang University College of Science and Technology, Jiangxi, 330029, China
}

Keywords: Campus football; independent colleges; football club; football extracurricular activities

\begin{abstract}
With the development of society, the state investment in higher education, college education is not only for culture and education, sports is also an indispensable university career. Colleges and universities learn from the form of foreign college sports club to carry out the "student-oriented" concept, which makes full use of university resources, and different forms of college sports reform was carried out .The basic situation of the football in Jiangxi Province and the main dilemma of the development process are investigated in this paper, and the corresponding measures for the main issues are provided, which has practical significance for the development of Jiangxi $\mathrm{P}$ independent campus football extracurricular movement. Besides, this paper aims to formulate and implement the level of football in Jiangxi independent college to provide the appropriate theoretical and decision-making reference to the related policies.
\end{abstract}

\section{Introduction}

Football is known as the world's largest sport, and campus football has a pivotal role as a breakthrough in campus sports. To carry out campus football activities, we should adhere to educate people, vigorously promote quality education, focus on technical capacity and further enhance the physical of students. Popularization and development of football, is an important part of China's sports industry, but also is an important part of building a sports power. At the same time, the development of football has become the focus of the topic. The State Council stressed that the development of relatively lagging football projects to develop long-term development planning and site facilities planning, and vigorously promote the campus football and Social soccer in the "State Council on the accelerated development of sports industry to promote sports consumption in a number of opinions" which was officially released in 2014. The hope of Chinese football career comes from the level of youth football. Therefore, the training of young people in all stages of football talent reserve force is the key to the development of Chinese football strength. At present, China's football reserve forces are small and the quality is not high enough. School is suitable for cultivating youth football reserve force platform, besides, the goal of campus football is to enhance the physical health of young people. China's campus football activities have formed a certain scale, which can be used as a sustainable long-term concept of sustainable development.

Independent colleges refers to the implementation of undergraduate education or higher institutions of higher learning and national institutions other than social organizations or individuals, and they use the non-state financial funds organized by the implementation of undergraduate education in higher education institutions[1]. Independent colleges cultivate the applied talents, and the proportion of personnel training weight of independent college evaluation reached $84.39 \%$ in 2016. Independent colleges have a higher starting point for development, if the system norms and policy guidance can be further strengthened in the education and teaching, and school model can further form their own characteristics, then it will be a vital part in China's higher education development process. 


\section{Status of Independent Campus Football at Home and Abroad}

The literature research method was used to comprehensively grasp and understand the status and results of the research related to this research topic, and determine the research task.

The development of foreign youth football is not only to improve the football technology, but mainly around the young football theory training, and to improve the overall quality of young people, and have advanced, scientific training concepts and methods. For example, British youth soccer reserve talent training system has formed a network of parallel organizational structure, a large team of young children and soccer team, so that the distribution of youth football reserve talent was in a "narrow" wide pyramid shape. Besides, Japanese football training is from the student interest, which focus on cultivating young people's hobbies. At the same time, they aim to improve the quality of adolescent education, so that young people have greater potential. South Korea attaches great importance to the training of youth soccer talent through the campus football activities of ordinary schools, including through the youth soccer club reserve personnel training system[2-4]. Compared to the foreign campus extracurricular football, in China, we found that independent campus football development is a long process, at present, it is still in the formation and exploration period, and the campus football development system has not yet formed. In addition, only the development direction of the system concept is put forward, and the specific content is not very deep. After five years of exploration and development, the construction of campus football in our country has begun to form. In the internal system, all levels of campus football leading group and relatively complete league mechanism has been established from top to bottom. However, in the external collaborative development, there are still large gaps, especially in the social and professional football club linkage. The "campus extracurricular football" league has had a lot of positive effects on the campus football activities of the university, and the development of the league has been supported by the majority of teachers. The parents also support "campus football extracurricular activities", which will carry out the popularity of China's football and promote its development . With the help of the colorful campus extracurricular football activities, students' amateur life is rich. The education department and the city football association can not effectively organize and manage the daily work of the "campus extracurricular football" league, which still needs further communication and collaboration[5-8].

\section{Research Method}

In the course of the study, we have read the books and literatures of foreign colleges and universities, and have reviewed more than 100 articles related to the research of domestic college sports and football clubs, including excellent master's and doctoral dissertations in recent years, Chinese college students' association, Chinese Football Association as well as the relevant provisions of the Chinese college football league and documents. We also visit the Internet to understand the National Association of College Students Sports Federation (NCAA) and the National Association of sports-related information, and to access information about college sports clubs, college football clubs[9]. There are four main methods used in this study. The first is the interview method. We interviewed experts with famous sports in football, and professors of teaching and research in colleges and universities, as well as some students. The second is the questionnaire survey, according to the research objects, we develop different questionnaires, and these questionnaires were issued to 13 independent colleges in Jiangxi Province. A total of two times questionnaires were performed, whose interval is 10 days. After the questionnaire was collected, the correlation coefficient was calculated by SPSS 18.0 , and the correlation coefficient was $0.88,0.87$ and 0.85 . The data showed no significant difference, and the reliability was in accordance with the statistical requirements. Besides, the 13 independent universities in Jiangxi Province were investigated also by telephone interview, WeChat research and personal visit. Figure 1 shows the procedure of this research. 


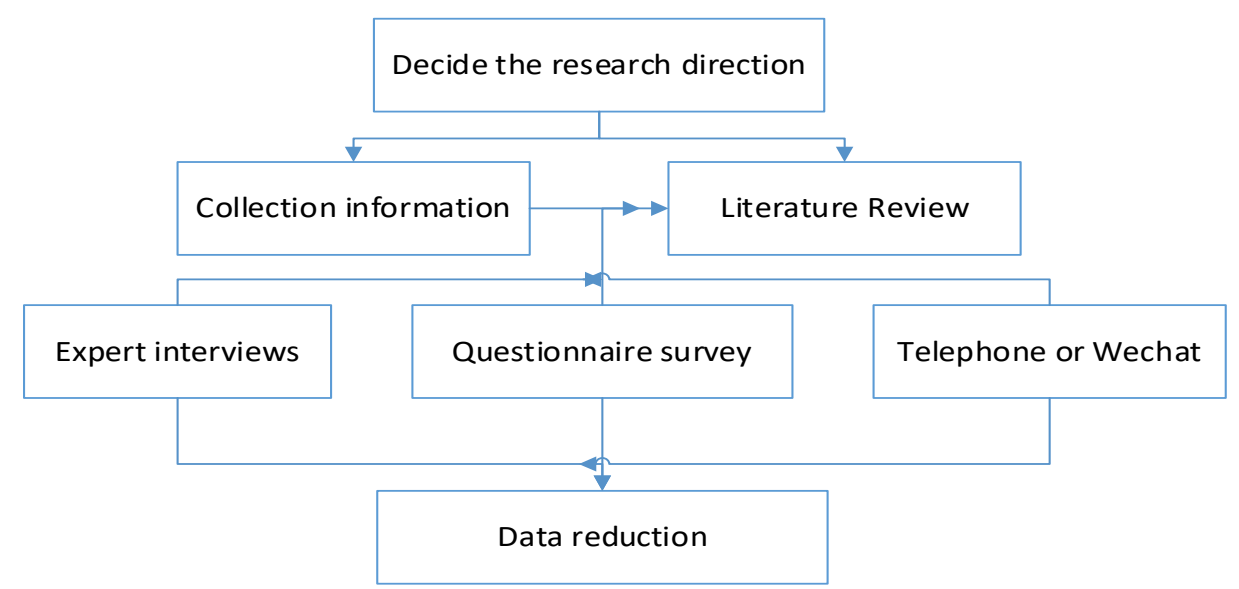

Figure 1. The procedures of this research.

\section{Results and Discussion}

\section{The Situation of the football extracurricular activities}

In this study, the situation of football extracurricular activities and the status quo of soccer club in independent colleges in Jiangxi province were studied. According to the pre-survey, as shown in Table 1, 70.3\% of the 13 independent schools in Jiangxi Province did not carry out extra-curricular activities on campus football. The campus football extracurricular activity class was an important part of campus football. In the course of more than three years of development, only 30 distribution schools have been implemented, accounting for only $29.7 \%$ of the total campus football school, while in the school, only $5.9 \%$ of the school carry out weekly football extracurricular activities, which the section number reached 3 and more than 3 sections.

Table 1. Statistics of Jiangxi Province campus football extracurricular activities $(\mathrm{N}=13)$

\begin{tabular}{|l|l|l|l|l|l|}
\hline Activitytimes per week & 0 & 1 & 2 & 3 & Over 3 \\
\hline Colleges & 6 & 3 & 2 & 1 & 1 \\
\hline Percentage(\%) & $46.2 \%$ & $23.2 \%$ & $15.4 \%$ & $7.6 \%$ & $7.6 \%$ \\
\hline
\end{tabular}

Besides, the management system of football extracurricular activities in Jiangxi independent colleges was also investigated. The management of football work is conducted of the vertical leadership model from the top to the bottom, that is, the Jiangxi school soccer association is led by the national school soccer association, and then each independent college is led by Jiangxi school soccer association. Jiangxi Province school soccer association is in charge of the Jiangxi campus football development planning, and activities, these independent colleges perform the clear request, including the overall framework of the relevant documents issued, and then schools develop specific activities based on relevant documents.

Targeted and planned program of activities is one of the important factors to ensure the smooth development of campus extracurricular activities, and the investigation was shown in table 2, it is found that for the campus football extracurricular activities of the 13 independent colleges, there are only two schools continue to develop specific program, while others are in the occasional program, or even in the absence of a program.

Table 2. Jiangxi Province campus football extracurricular activities program situation

\begin{tabular}{|l|l|l|l|}
\hline & $\begin{array}{l}\text { Sustainable } \\
\text { planning }\end{array}$ & $\begin{array}{l}\text { Occasional } \\
\text { olanning }\end{array}$ & Never \\
\hline Colleges & 2 & 3 & 8 \\
\hline Percentage(\%) & $15.4 \%$ & $23.1 \%$ & $61.5 \%$ \\
\hline
\end{tabular}


As for the way of campus football extracurricular activities, we have a research about the variety of the football extracurricular activities. Independent colleges and universities of Jiangxi Province carry out the main school football activities, including school football activities, football cultural activities, class football and school football. As shown in Figure 2, 13 independent institutions, the campus football to carry out the main way to class football teaching, accounting for $53 \%, 16 \%$ after school training, school soccer game accounted for $13 \%$, class football game accounted for $9 \%$, and $3 \%$ is for extracurricular soccer league, extracurricular soccer and soccer cultural activities accounted for $6 \%$. This may be because the students are mainly focused on the school work and other activities. With the growth of age and less exams, students enthusiasm for football increases, spontaneous extracurricular training increased, the corresponding increase in school competition.

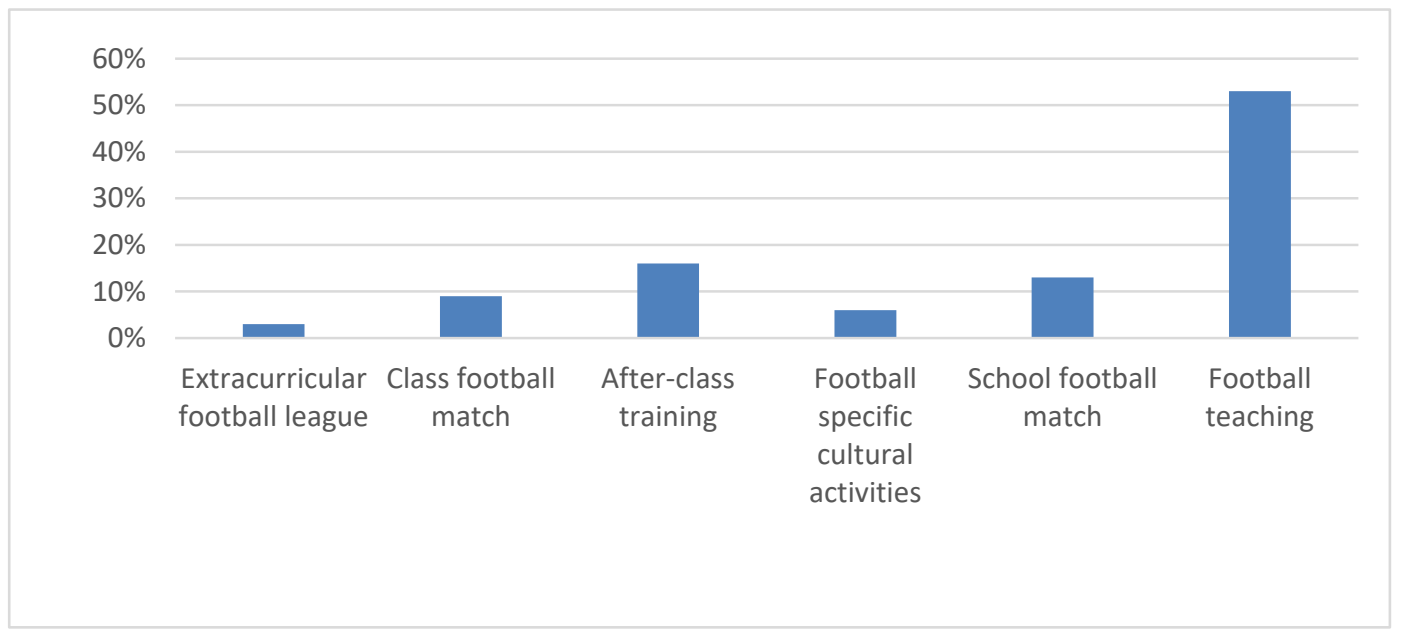

Figure 2. The situation of football extracurricular activities carried out in 13 independent colleges.

\section{The Situation of football club}

The sports club in colleges and universities is the continuation of physical education. The significance of the existence of the sports club In addition to all the college students to popularize various sports, physical fitness, to achieve the purpose of life-long movement, there is an important duty is to train high-level sports teams to participate in the competition. From the view of the reform and development of PE curriculum in colleges and universities at present, it is very suitable for the current situation of college sports. The research on the sports club in colleges and universities in our country is endless, mainly focusing on the development of the sports club in colleges and universities, the management, operation and organization of the study, the sports club in colleges and universities, equipment and sports club assessment and evaluation system, as well as the construction of sports clubs in colleges and universities. Football is the world's first movement, college students are full of enthusiasm for football, many colleges and universities in order to adapt to the needs of college football development, increased investment in football and management efforts, and the colleges and universities have established football club to participate in college football league. According to the survey, a total of seven schools have set up a football club, and, the members two of college football clubs reaches 50 . The member number of other clubs is mostly between 20 and 30, the establishment of 13 independent institutions football club and the number of clubs. These numbers do not mean that only these people like to participate in football, some students also like football, but for some reason, they don't participate in the football club, so the data is only an objective reflection of the school football club popularity.

Table 3. Jiangxi Province campus football club(N=7)

\begin{tabular}{|l|l|l|l|l|}
\hline Members & Less than 20 & $20-30$ & $30-40$ & Over 40 \\
\hline Colleges & 0 & 4 & 1 & 2 \\
\hline
\end{tabular}


Although as college students, there is no the pressure of high school stage, but they also have to face the new learning tasks. In addition to the weekly sports, they should have a certain time of exercise, and football is a multiplayer movement, which can enhance the sense of cooperation in the movement at the same time. A large part of the students play a lot of games, the quality of modern college students is very worrying, generally reflected in the system test when there will be a large part of the students can not pass because of their own reasons. Some professional studies are tense, but most of the students have plenty of extra time. There is also a reason that there is no coach to guide the club training which makes the club is in name only.

\section{Summary}

Jiangxi Province has strengthened the management and construction of campus football and good results have been achieved. However, there are still some problems to be resolved. The campus football extracurricular activities of the organization should be improved, together with a clear campus football extracurricular activities management organization. The establishment of the school football extracurricular activities should be carried out often to ensure the smooth implementation of the relevant rules and regulations. Rich extracurricular activities in the form of group activities can be the basic form of organization, and a reasonable integration into individual activities and group activities is needed to better stimulate students interest in football, but also to meet the campus football extracurricular activities of the venue, equipment and other facilities.

\section{References}

[1] Katz P M. High-Tech or High-Touch? Online Learning and Independent Higher Education. Innovations in Teaching and Learning. Research Brief 5[J]. Council of Independent Colleges, 2016.

[2] Based on Belt and Road Strategy[J]. Agro FOOD Industry Hi Tech, 2017, 28:1.

[3] LU D A I. Research on the Professional Management System of the Football Sports of College Students[J]. Agro FOOD Industry Hi Tech, 2017, 28: 1.

[4] Hong F. Analysis of Factors Affecting Campus Football in Small and Medium-sized Cities of Western China and Solutions- - Take Dazhou, Sichuan as an Example[J]. Bulletin of Sport Science \& Technology, 2015, 5: 029.

[5] Jian X. A study on actuality and countermeasure of the campus football in our school[J]. Journal of Jiamusi Education Institute, 2013, 9: 265.

[6] QI H, ZHONG H. Analysis on Women's Football Development Condition between China and Japan[J]. Bulletin of Sport Science \& Technology, 2014, 6: 009.

[7] Cui L, Feng B. Research on the Campus Football Culture and Sustainable Development[J]. 2015.

[8] Ritchie D, Hopkins W G, Buchheit M, et al. Quantification of training and competition load across a season in an elite Australian football club[J]. International journal of sports physiology and performance, 2016, 11(4): 474-479.

[9] Walsh M. Club Identity/Class Identity: Negotiations of Popular Memory by Followers of the Australian Football League[J]. The International Journal of the History of Sport, 2015, 32(13): 1593-1610. 